\title{
Interest of the Total Elbow Arthroplasty in Pathological Fractures of the Distal Humerus
}

\author{
Mohamed Amine Mahraoui1 ${ }^{*}$, Amine Belmoubarik1, Haitam Abou Ali², Otmane Hiba1, \\ Abderrahim Rafaoui'2, Ricardo Da Silva ${ }^{3}$, Eric Bacheville ${ }^{3}$, Hani-Jean Tawil ${ }^{3}$ \\ ${ }^{1}$ Department of Orthopaedic Surgery, Ibn Rochd Hospital, Wing 4 Casablanca, Morocco \\ ${ }^{2}$ Department of Orthopaedic Surgery, Ibn Rochd Hospital, Pavilion 32, Casablanca, Morocco \\ ${ }^{3}$ Orsay Hospital, Orsay, France \\ Email: *Mohamedamine.mahraoui@gmail.com, aminovich2005@gmail.com,dr-othmane@hotmail.fr, \\ rafaoui2525@yahoo.fr, silva2015@gmail.com, e.bacheville@gmail.com,j.h.tawil@hotmail.fr
}

Received 16 November 2015; accepted 4 December 2015; published 8 December 2015

Copyright (C) 2015 by authors and OALib.

This work is licensed under the Creative Commons Attribution International License (CC BY).

http://creativecommons.org/licenses/by/4.0/

C. (i) Open Access

\section{Abstract}

Fractures of the distal humerus account for $5 \%$ of osteoporotic fractures in patients over 60 years. The osteoporotic field, comorbidities, and joint comminutions make it difficult to support. The objective of our work is to show the interest of the total elbow arthroplasty in pathological fractures of the distal humerus. We report a unique case of a pathological fracture of the distal end immediately treated by total elbow arthroplasty in a 82-year-old patient whose biopsy reveals an evocative metastasis of clear cell adenocarcinoma of renal origin. In fractures of the distal humerus disease in the elderly, the absolute necessity of rapid recovery of daily life activities can move towards a total joint arthroplasty or hemiarthroplasty. Total joint replacement is an alternative to the trauma in the elderly elbow. It uses semi-constrained implants allowing stable mounting and early mobilization through self-rehabilitation.

\section{Keywords}

Distal Humerus, Pathological Fracture, Elbow Arthroplasty

Subject Areas: Orthopedics, Surgery \& Surgical Specialties

\section{Introduction}

Fractures of the distal humerus account for 5\% of osteoporotic fractures in patients over 60 years. The osteopo${ }^{*}$ Corresponding author.

How to cite this paper: Mahraoui, M.A., Belmoubarik, A., Ali, H.A., Hiba, O., Rafaoui, A., Da Silva, R., Bacheville, E. and Tawil, H.-J. (2015) Interest of the Total Elbow Arthroplasty in Pathological Fractures of the Distal Humerus. Open Access Library Journal, 2: e2179. http://dx.doi.org/10.4236/oalib.1102179 
rotic field, comorbidities, and articular comminutions make it difficult to support [1].

The objective of our work is to show the interest of the total elbow arthroplasty in pathological fractures of the distal humerus.

\section{Case Report}

This is a patient 82 years old, right-handed, having as an antecedent hypertension, atrial fibrillation, prostatectomy and parotid cyst.

Our patient had pain in the right elbow for three weeks, following a wrong move causing acute pain and total functional impotence of the right arm.

On examination: painful elbow edematous, with bruises without neurovascular disorders downstream.

Our patient underwent radiographic assessment is an $\mathrm{x}$-ray of the right elbow and face profile

Our patient underwent radiographic assessment is an $\mathrm{x}$-ray radiography face and right elbow profile (Figure 1) with an elbow CT (Figure 2) which has objectified a supra-condylar humerus fracture on a lytic lesion.

A staging is required because of a bone scan which objectified the absence of other attachment points than the elbow.

Thoracoabdominal scan which showed two lung nodules on the right and another left and a tumor mass in the left kidney (62 mm/58 mm).

Our patient underwent total elbow prosthesis (Figure 3): the surgical approach was later centered on the olecranon, neurolysis of the ulnar nerve, para-internal and external passing triceps.

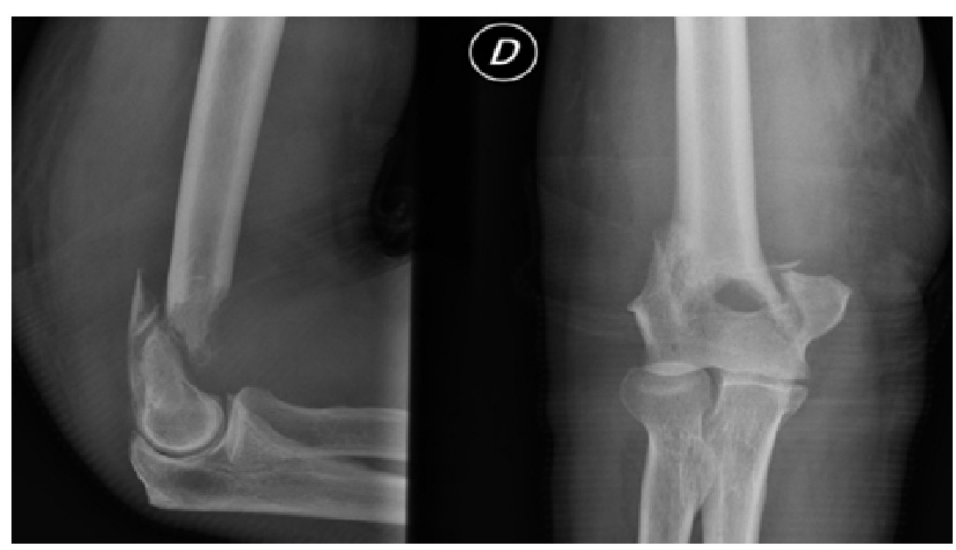

Figure 1. X-ray radiography face and right elbow profile.

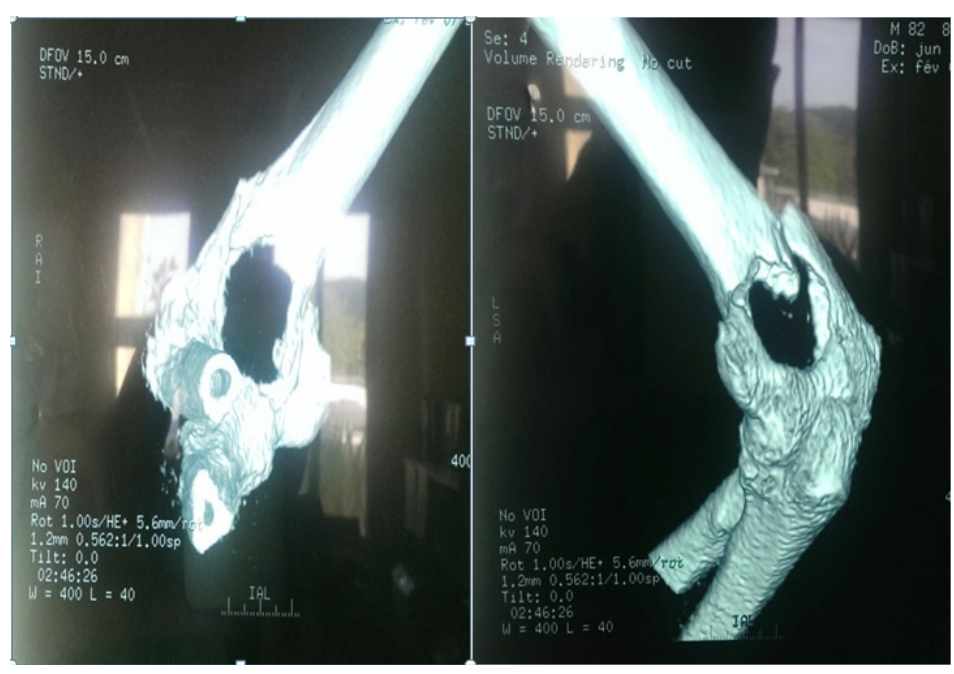

Figure 2. Elbow CT image showing a supracondylar humerus fracture on a lytic lesion. 


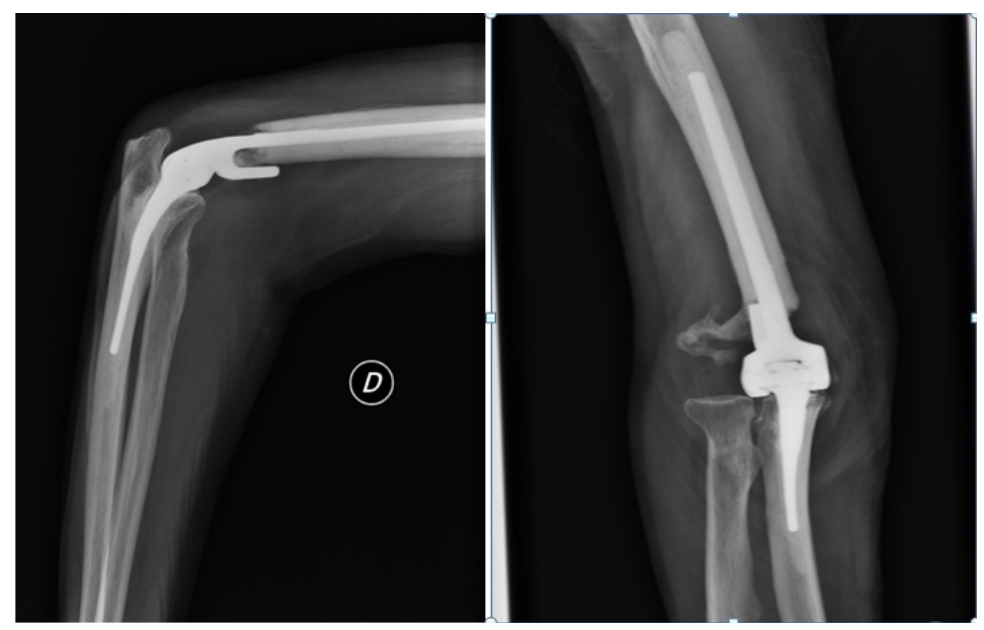

Figure 3. Image showing the X-ray control of the elbow prosthesis.

An intraoperative biopsy objectified an evocative bone metastasis of a clear cell carcinoma of renal cells. The postoperative course was simple, with almost complete recovery of range of motion.

The patient was transferred to a specialized center for additional support.

\section{Discussion}

The emergence of modern equipment screw locked mono or polyaxial allowed to modify the indications in fractures of the distal humerus, and expand the possibilities of osteosynthesis fractures on osteoporotic bones or pathological [2]. The primary objective of the bone of the distal end of the humerus is to achieve perfect primary stability of the fracture, allowing early rehabilitation essential for the recovery of normal mobility. In fractures of the distal humerus after low-energy trauma, and osteoporosis in the elderly, the importance of fracture comminution and the absolute necessity of rapid recovery of daily life activities can move towards a total joint arthroplasty or hemiarthroplasty [3] [4]. Complications of these fractures are common and can associate with varying degrees stiffness, periarticular ossification, malunion or nonunion. Treatment of sequelae is difficult to justify the optimal treatment of recent fractures.

\section{Conclusion}

Total joint replacement is an alternative to the trauma in the elderly elbow. It uses semi-constrained implants allowing stable mounting and early mobilization by self rehabilitation.

\section{Contribution of Authors}

All authors participated in the preparation of this work.

\section{Conflicts of Interest}

No conflicts of interest were reported.

\section{References}

[1] Miller, A.N. and Beingessner, D.M. (2013) Intra-Articular Distal Humerus Fractures. Orthopedic Clinics of North America, 44, 35-45. http://dx.doi.org/10.1016/j.ocl.2012.08.010

[2] Bégué, T. (2006) Fractures de l'extrémité inférieure de l’humérus. In: Mansat Meditor. Chirurgie de l'épaule et du coude. Masson Edition, Paris, 148-156.

[3] Sanchez-Sotelo, J. (2012) Distal Humeral Fractures: Role of Internal Fixation and Elbowarthroplasty. Instrument Rating Course, 61, 203-213.

[4] Mansat, P. and Bonnevialle, N. (2010) Prothèse totale du coude de première intention. EMC, Techniques Chirurgicales-Orthopédie-Traumatologie, 5, 1-17. http://dx.doi.org/10.1016/s0246-0467(10)51005-5 